\title{
Polycyclic Aromatic Hydrocarbons (PAHs) in sediment from Poyang lake under the condition of drying- wetting cycles
}

YUNCHAO ZHANG ${ }^{1}$,DAN YANG ${ }^{3}$, LIDAO MAO ${ }^{2}$,JINHONG LIU $^{1}$, YUAN ZHANG $^{1}$ AND SHIHUA QI ${ }^{12 *}$

${ }^{1}$ State Key Laboratory of Biogeology and Environmental Geology, China University of Geosciences (CUG),

Wuhan 430074, China (zyc@cug.edu.cn)

${ }^{2}$ School of Environmental Studies, CUG, China

(*correspondence:shihuaqi@cug.edu.cn)

${ }^{3}$ School of Engineering Studies, CUG, China

Polycyclic aromatic hydrocarbons (PAHs) containing typically 2 to 8 fused aromatic rings are ubiquitous environmental contaminants produced by high-temperature reactions, such as incomplete combustion and pyrolysis of fossil fuels and other organic materials. Changes in climate and human activities may influence lake water balances, resulting in significant alterations in lake water level and damage to lake functions. A prominent example of the recession is Poyang lake, the largest freshwater lake in China. The considerable seasonal variation in the lake level is about $10 \mathrm{~m}$, and creates extensive mudflats with an maximum ephemeral area of some $3000 \mathrm{~km}^{2}$. Accordingly, this enabled the detailed investigation of the spatial variations in PAH concentrations in sediments due to the influence of watercovering conditions.

The total concentrations of PAHs in sediments ranged from 17 to $774 \mathrm{ng} / \mathrm{g}$ with a mean value of $176 \pm 199 \mathrm{ng} / \mathrm{g}$ and PAH concentrations for wet season $(197 \pm 171 \mathrm{ng} / \mathrm{g})$ were higher than the corresponding values for dry season $(156 \pm 227$ $\mathrm{ng} / \mathrm{g}$ ) in most locations. the concentrations of high molecular weight PAHs (4-6 rings) accounted for $57.0 \pm 21.2 \%$, which were higher than those of low molecular weight PAHs (2-3 rings) in sediment samples. The radios of Flu/(Flu+Pyr) and $\mathrm{BaA} /(\mathrm{BaA}+\mathrm{Chr})$ indicate that the major sources of sedimentary PAHs were biomass and coal combustion. In addition, the potential ecological risks of most PAHs in the sediments of Poyang Lake was limited, but sediments in dry season had certain carcinogenic health risks to people who live around Poyang Lake. The evaluation of potential biological effects suggested that the adverse biological toxicity effect would occur occasionally in wet season. 